\title{
Uji Kandungan Hidroquinon Pada \\ Sediaan Krim Racikan Dokter Dan Krim Pencerah Wajah Dengan Menggunakan Spektrofotometer Uv
}

\author{
Ni Putu Rahayu Artini \\ Program Studi Teknologi Laboratorium Medik Fakultas Ilmu-Ilmu Kesehatan \\ Universitas Bali Internasional \\ Email: artinirahayu967@gmail.com
}

\begin{abstract}
Tanggal Submit:

31 Desember 2020

Tanggal Review:

22 Februari 2021

Tanggal Publish

Online: 18 Juni 2021

Hydroquinon is a chemical used as a skin lightener. However, its effectiveness began to be questioned after the emergence of a study showing that hydroquinone can trigger cancer. This study aims to analyze the hydroquinone content of several doctor-made creams and branded facial lightening creams circulating in Denpasar. This research is an experimental research. The sample used consisted of five samples of doctor-made creams coded D1-D5, while branded lightening creams were coded P1-P10. Based on the results of the analysis, the wavelength of $293 \mathrm{~nm}$ is the wavelength that provides maximum absorption with the equation $y=0.023 x+$ 0.005 with a value of $R 2=0.996$. 0.023. The results of the analysis showed that all samples of the doctor's cream contained hydroquinone with an average of $11.9322 \mathrm{ppm}$ or $1.1932 \%$ and did not exceed the BPOM regulations, namely 5\% for cream preparations prescribed by doctors. And all samples of branded facial lightening creams in Denpasar City contain hydroquinone with an average hydroquinone level of 3,987 ppm or $0.3987 \%$ and do not exceed the BPOM regulations, which is $2 \%$ for whitening cream preparations that are sold freely without a doctor's prescription.
\end{abstract}

Keywords : hydroquinone, cream, spectrophotometer UV

\section{PENDAHULUAN}

Sebagian besar wanita Indonesia menginginkan kulit putih, bersih dan cerah untuk menjaga penampilan agar tetap menarik dan indah dilihat, karena pada zaman modern ini, penampilam yang menarik adalah salah satu syarat mutlak dalam dunia kerja dan pergaulan. Untuk memenuhi keinginan itu, mereka menggunakan berbagai cara dari perawatan kulit alami hingga perawatan yang sangat instan dengan berbagai jenis kosmetik tanpa memperhatikan dengan lebih teliti jenis bahan kimia yang terkandung dalam kosmetik tersebut akan menimbulkan efek yang dapat membahayakan bagi kulit (Arief, 2009). 
Efek yang ingin diharapkan

ketika menggunakan produk krim pemutih adalah kulit jadi lebih putih, bersinar, dan halus. Padahal sebenarnya krim pemutih lebih bermaksud pada perawatan kulit wanita agar berpenampilan cerah, sehat dan segar. Artinya pemutih kulit atau whitening yang terdapat dalam produk kosmetik berfungsi untuk mencerahkan, bukan memutihkan hanya melindungi kulit dari bahaya radiasi sinar UV A. Bahan kimia berbahaya yang sering digunakan dalam krim pemutih adalah merkuri inorganik dan hidrokuinon (Sunarko, 2007).

Dikalangan wanita Asia dan Afrika hidrokuinon merupakan bahan kimia yang populer digunakan sebagai pencerah kulit. Akan tetapi, keefektifannya mulai diragukan setelah munculnya suatu penelitian yang menunjukkan bukti-bukti bahwa hidrokuinon dapat memicu kanker, jika dipergunakan dalam kurun waktu yang lama. Hal ini diperkuat lagi pada bulan Agustus 2006, oleh Food and Drug Administration atau yang disingkat dengan FDA melarang semua produk kosmetik mengandung hidrokuinon (Asih, 2006). FDA menetapkan setiap produk mengandung hidrokuinon dianggap obat dan hanya dapat dibeli dengan resep dokter (Draelos \& Zoe, 2005).
Hidrokuinon digolongkan ke obat daftar $\mathrm{G}$ (obat keras) karena untuk memperolehnya harus dengan resep dokter. Akan tetapi pemakaian jangka panjang senyawa hidrokuinon ini akan menghancurkan produksi melanin, sehingga membuat kulit kehilangan fungsi perlindungannya langsung terhadap sinar matahari dan efek eksternal lainnya (Baran, 2008).

Kadar hidrokuinon pada krim kosmetika yang beredar dipasaran hanya diperbolehkan maksimal 2\% (BPOM RI, 2005). Kadar hidrokuinon yang melebihi $5 \%$ dapat menimbulkan kemerahan dan rasa terbakar pada kulit. Bahaya pemakaian obat keras ini tanpa pengawasan dokter dapat menyebabkan iritasi, memerahnya kulit, rasa terbakar, kelainan ginjal, kanker darah, dan kanker hati (Saito , 1994).

Karena masyarakat percaya sepenuhnya kepada ahli kecantikan, yaitu dokter spesialis kulit seringkali tidak peduli apakah kosmetika yang diberikan telah terdaftar di BPOM atau belum. Kesadaran dokter juga diperlukan sehingga tidak hanya mendahulukan keuntungan tetapi juga keamanan. Namun, tidak luput juga bahwa beberapa kosmetika yang telah memiliki ijin edar dan terdaftar di BPOM kadang juga masih mengandung bahan aktif hidrokuinon tanpa 
menginformasikan pada bagian

ingredient etiket.

Penetapan kadar hidrokuinon

dapat dilakukan dengan beberapa

metode antara lain dengan titrasi redoks

(Depkes RI, 2005), spektrofotometri UV

(Pedro, 2007), kolorimetri (Sunarko,

2007), thin layer chromatography

(Siddique \& Saima, 2012), high

performance liquid chromatography

(BPOM, 2005), dan gas

chromatography mass spectrofotometri

(Saito et al., 1994). Penetapan secara spektrofotometri UV merupakan metode yang paling mudah, cepat, dan murah karena menggunakan sedikit bahan kimia, namun memiliki akurasi dan presisi yang baik. Oleh karena itu, pada penelitian ini akan dilakukan analisis kandungan hidrokuinon pada beberapa sediaan krim racikan dokter dan krim pencerah wajah bermerek yang beredar di Kota Denpasar.

\section{METODE PENELITIAN}

\section{Sampel dan Bahan Penelitian}

Sampel yang digunakan pada penelitian ini adalah sediaan krim racikan dokter dan krim pencerah wajah. Bahan kimia yang digunakan methanol p.a., aquades, dan standar hidrokuinon.

Peralatan yang digunakan pada penelitian ini terdiri dari peralatan gelas yaitu, spatula, pipet volume $10 \mathrm{~mL}$ (Pyrex), labu ukur $25 \mathrm{~mL}$ (Pyrex), dan beaker glass $50 \mathrm{~mL}$ (Pyrex). Alat - alat yang digunakan pada penelitian ini adalah spektrofotometer UV (merk AMTAST AMV 11) dan neraca analitik (merk Bel AB M214Ai).

\section{Prosedur Penelitian}

Sampel berupa sediaan krim racikan dokter dan krim pencerah wajah bermerk yang beredar di daerah Denpasar dan Badung. Larutan standar dengan seri 1 ppm; 2 ppm; 4 ppm; 8 ppm dan 10 ppm dibuat dari larutan induk standar hidrokuinon $40 \mathrm{ppm}$. Masing - masing konsentrasi dibuat dengan volume $10 \mathrm{~mL}$ menggunakan methanol. Methanol digunakan sebagai blanko. Kemudian sampel ditimbang sebanyak $\pm 0,05$ gram dan dicatat berat penimbangannya, kemudian dilarutkan dalam $25 \mathrm{~mL}$ methanol. Uji validasi panjang gelombang maksimum dilakukan menggunakan larutan standar 10 ppm dengan spektrofotometer UV dari panjang gelombang $285 \mathrm{~nm}-295$ $\mathrm{nm}$. Standar dan sampel yang telah siap kemudian dianalisis menggunakan spektrofotometer UV dari panjang gelombang maksimum yang diperoleh dan dilakukan analisis data dari persamaan regresi linear yang diperoleh (Gandjar dan Rohman, 2007). 
HASIL

Sebanyak lima sampel krim racikan dokter yang membuka praktek dokter kulit dan $10 \mathrm{krim}$ pencerah wajah digunakan untuk analisis kandungan hidroquinon. Untuk krim racikan dokter diberi kode D1-D5, sedangkan krim pencerah bermerk diberi kode P1-P10.

\section{Penentuan Panjang Gelombang \\ Maksimum}

Penentuan panjang gelombang maksimum untuk pengukuran serapan maksimum hidroquinon dilakukan dengan menggunakan spektrofotometer UV dari panjang gelombang $285 \mathrm{~nm}-$ $295 \mathrm{~nm}$ dengan menggunakan larutan standar 10 ppm. Nilai absorbansi disajikan pada Tabel 1.

Tabel 1. Penentuan panjang gelombang maksimum pengukuran hidroquinon

\begin{tabular}{ccc}
\hline No. & Panjang gelombang $(\mathbf{n m})$ & Absorbansi \\
\hline 1. & 285 & 0,190 \\
\hline 2. & 286 & 0,196 \\
\hline 3. & 287 & 0,201 \\
\hline 4. & 288 & 0,204 \\
\hline 5. & 289 & 0,213 \\
\hline 6. & 290 & 0,220 \\
\hline 7. & 291 & 0,225 \\
\hline 8. & 292 & 0,228 \\
\hline 9. & 293 & 0,230 \\
\hline 10 & 294 & 0,228 \\
\hline 11. & 295 & 0,223 \\
\hline
\end{tabular}

Berdasarkan Tabel 1. Panjang gelombang maksimum dari rentang 285 $\mathrm{nm}$ - $295 \mathrm{~nm}$ dengan menggunakan spektrofotometer UV, diperoleh dari pengukuran larutan standar hidroquinon 10 ppm adalah 0,230 pada panjang gelombang $293 \mathrm{~nm}$. Panjang gelombang maksimum adalah panjang gelombang yang memberikan serapan tertinggi (Irnawathi, 2016).

\section{Penentuan Kurva Standar}

Pengukuran kurva standar larutan hidroquinon dilakukan dengan menggunakan larutan standar seri 0 ppm; 1 ppm; 2 ppm; 4 ppm; 8 ppm dan 10 ppm yang dibuat dari larutan induk standar hidrokuinon $40 \quad$ ppm. Pengukuran serapan dilakukan pada panjang gelombang $293 \mathrm{~nm}$. Hasil penentuan nilai larutan standar disajikan pada Tabel 2 dan Gambar 1. 
Tabel 2. Penentuan kurva standar hidroquinon

\begin{tabular}{cc}
\hline Konsentrasi (ppm) & Absorbansi \\
\hline 0 & 0,000 \\
\hline 1 & 0,026 \\
\hline 2 & 0,042 \\
\hline 4 & 0,086 \\
\hline 8 & 0,175 \\
\hline 10 & 0,230
\end{tabular}

Berdasarkan hasil penentuan

nilai absorbansi larutan standar hidroquinon, semakin tinggi konsentrasi larutan standar, nilai absorbansi akan semakin tinggi. Sehingga diperoleh kurva larutan standar hidroquinon (Irnawathi, 2016).

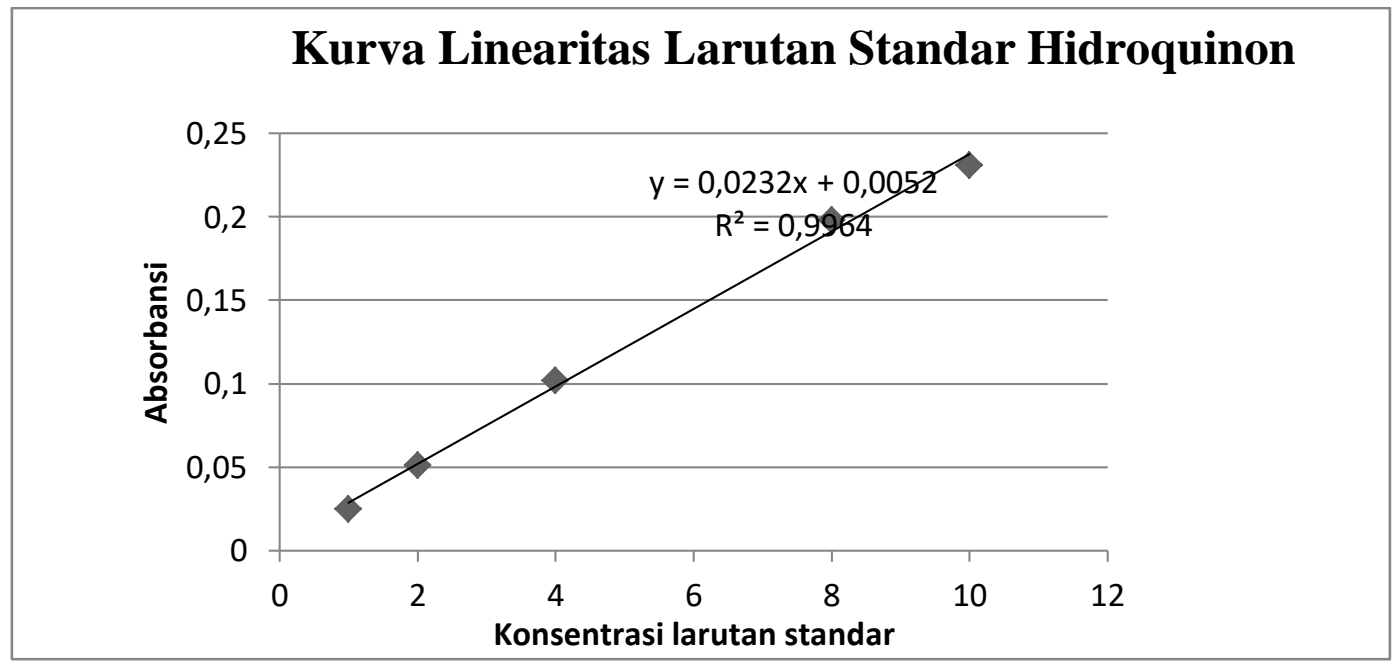

Gambar 1. Kurva linearitas larutan standar hidroquinon

Berdasarkan Gambar 1. Kurva linearitas larutan standar hidroquinon membentuk garis lurus (linear). Kurva tersebut memberikan respon dari hasil transformasi matematika, sehingga diperoleh persaman regresi linear antara konsentrasi larutan standard dan absorbansi adalah $\mathrm{y}=0,023 \mathrm{x}+0,005$ dengan nilai $\mathrm{R}^{2}=0,996$. 0,023 merupakan nilai slode dan 0,005 adalah nilai intersep, sedangkan 0,996 adalah nilai koefisien korelasi. Berdasarkan garfik, nilai koefisien korelasi mendekati nilai 1 , yang menyatakan bahwa terjadinya peningkatan serapan analit berbanding lurus dengan konsentrasi (Miller dan Miller, 2010). 
Kadar Hidroquinon Pada Sampel

Krim Racikan Dokter
Hasil pemeriksaan kadar hidroquinon pada sampel krim racikan dokter disajikan pada Tabel 3.

Tabel 3. Kadar hidroquinon krim racikan dokter di Kota Denpasar

\begin{tabular}{cccc}
\hline No. & Kode krim racikan dokter & Kadar $(\mathbf{p p m})$ & Hidroquinon $(\%)$ \\
\hline 1. & D 1 & 11.275 & 1,1275 \\
\hline 2. & D2 & 7.726 & 0,7726 \\
\hline 3. & D3 & 7.266 & 0,7266 \\
\hline 4. & D $~$ & 16.997 & 1,6997 \\
\hline 5. & D5 & 16.397 & 1,6397 \\
\hline & Rata-rata & $\mathbf{1 1 . 9 3 2 2}$ & $\mathbf{1 , 1 9 3 2}$ \\
\hline
\end{tabular}

Berdasarkan table diatas, kadar hidroquinon krim racikan dokter terendah adalah pada kode D3 dengan kadar $7.266 \mathrm{ppm}$ atau $0,07266 \%$ dan kadar hidroquinon tertinggi adalah pada kode D4 dengan kadar 16.997 ppm atau $1,6997 \%$ dan rata-rata $11.9322 \mathrm{ppm}$ atau $1,1932 \%$.

\section{Kadar Hidroquinon Pada Sampel} Krim Pencerah Wajah Bermerk di Kota Denpasar

Hasil pemeriksaan kadar hidroquinon pada sampel krim pencerah wajah bermerk di Kota Denpasar disajikan pada Tabel 4.

Tabel 4. Kadar hidroquinon krim pencerah wajah bermerk di Kota Denpasar

\begin{tabular}{cccc}
\hline No. & Kode krim pencerah wajah & Kadar $(\mathbf{p p m})$ & Hidroquinon $(\%)$ \\
\hline 1. & P1 & 1.310 & 0,1310 \\
\hline 2. & P2 & 1.250 & 0,1250 \\
\hline 3. & P3 & 2.456 & 0,2456 \\
\hline 4. & P4 & 2.641 & 0,2641 \\
\hline 5. & P5 & 3.380 & 0,3380 \\
\hline 6. & P6 & 14.836 & 1,4836 \\
\hline 7. & P7 & 3.500 & 0,3500 \\
\hline 8. & P & 6.336 & 0,6336 \\
\hline 9. & P9 & 826 & 0,0826 \\
\hline 10. & P10 & 3.336 & 0,3336 \\
\hline & Rata-rata & $\mathbf{3 . 9 8 7}$ & $\mathbf{0 , 3 9 8 7}$
\end{tabular}

Berdasarkan tabel diatas, kadar hidroquinon krim pencerah bermerk di Kota Denpasar terendah adalah pada kode P9 dengan kadar $826 \mathrm{ppm}$ atau $0,0826 \%$ dan kadar hidroquinon tertinggi adalah pada kode P6 dengan 
kadar $14.836 \mathrm{ppm}$ atau $1,4836 \%$ dan rata-rata $3.987 \mathrm{ppm}$ atau $0,3987 \%$.

\section{PEMBAHASAN}

Jumlah sampel krim kosmetik yang digunakan pada penelitian ini adalah 15 produk, yang terdiri dari lima krim racikan dokter dan 10 krim pencerah wajah bermerk yang beredar di Kota Denpasar. Lima krim racikan dokter keseluruhan adalah krim malam sedangkan untuk 10 krim pencerah merupakan day krim atau krim harian yang dapat dipakai pada pagi, siang, maupun malam hari. Untuk menganalisis kandungan hidroquinon yang ditambahkan ke dalam sediaan krim kecantikan dilakukan penentuan pengukuran absorbansi maksimum pada larutan standar hidroquinon dari panjang gelombang $285 \mathrm{~nm}-295 \mathrm{~nm}$. Berdasarkan hasil analisis panjang gelombang $293 \mathrm{~nm}$ adalah panjang gelombang yang memberikan serapan maksimum. Dengan demikian penentuan kurva linearitas larutan standar hidroquinon dapat diperoleh dengan persamaan $\mathrm{y}=0,023 \mathrm{x}+0,005$ dengan nilai $\mathrm{R}^{2}=0,996$. 0,023 merupakan nilai slode dan 0,005 adalah nilai intersep, sedangkan 0,996 adalah nilai koefisien korelasi. Berdasarkan garfik, nilai koefisien korelasi mendekati nilai 1 , yang menyatakan bahwa terjadinya peningkatan serapan analit berbanding lurus dengan konsentrasi (Miller dan Miller, 2010).

\section{Kadar Hidroquinon Pada Sampel}

\section{Krim Racikan Dokter di Kota}

Denpasar

$\begin{array}{ccc}\text { Krim racikan dokter } & \text { yang } \\ \text { digunakan sebagai } & \text { sampel } & \text { pada }\end{array}$ penelitian ini adalah krim malam yang dibeli pada klinik-klinik kecantikan dokter kulit. Analisis dilakukan dengan menggunakan spektofotometer UV. Berdasarkan Tabel 3, kadar hidroquinon krim racikan dokter terendah adalah pada kode D3 dengan kadar 7.266 ppm atau $0,07266 \%$ dan kadar hidroquinon tertinggi adalah pada kode D4 dengan kadar 16.997 ppm atau 1,6997\% dan rata-rata $11.9322 \mathrm{ppm}$ atau $1,1932 \%$. Berdasarkan hasil diatas, kadar hidroquinon pada krim racikan dokter tidak melebihi $5 \%$ untuk sediaan krim yang diresepkan oleh dokter sehingga aman digunakan (BPOM RI, 2007).

Krim racikan dokter yang dibeli keseluruhan merupakan jenis produk krim malam. Krim malam mengandung lebih banyak moisturizer dibandingkan dengan krim pagi, yang berfungsi untuk menjaga wajah agar tetap lembab hingga pagi. Krim malam mengandung moisturizer yang tinggi daan dilengkapi dengan bahan yang memiliki fungsi masing - masing seperti, untuk anti aging atau penuaan kulit, umumnya krim malam mengandung retinol, 
glycolic acid, hyaluronic acid, vitamin A dan vitamin E (Wasitaatmadjo, 2007).

Namun, karena bertujuan untuk memperbaiki dan meregenerasi kulit, sebagian besar kandungan pada krim malam memiliki khasiat untuk mencegah terjadinya proses pengeriputan dan penuaan pada kulit wajah. Kandungan moisturizer pada krim malam ini terkenal lebih kaya daripada krim siang, hal ini disebabkan karena mampu melembabkan kulit sepanjang malam agar proses regenerasi sel-sel kulit tetap dapat berjalan lancar serta dapat menghambat pertumbuhan melanin yang dapat menimbulkan flek hitam (Draelolos \& Zoe, 2005).

\section{Kadar Hidroquinon Pada Sampel} Krim Pencerah Wajah Bermerk di

\section{Kota Denpasar}

Krim pencerah bermerk yang digunakan sebagai sampel pada penelitian ini diambil di beberapa supermarket yang tersebar di Kota Denpasar. Secara keseluruhan sampel krim pencerah wajah yang diteliti telah berijin POM NA. Krim pencerah yang diteliti adalah krim yang dapat digunakan pada pagi dan malam hari. Berdasarkan Tabel 4, kadar hidroquinon krim pencerah bermerk di Kota Denpasar terendah adalah pada kode P9 dengan kadar $826 \mathrm{ppm}$ atau $0,0826 \%$ dan kadar hidroquinon tertinggi adalah pada kode P6 dengan kadar 14.836 ppm atau $1,4836 \%$ dan rata-rata $3.987 \mathrm{ppm}$ atau $0,3987 \%$. Secara keseluruhan kadar hidroqunin pada krim pencerah wajah bermerk tersebut tidak melebihi dari $2 \%$ untuk sediaan krim pemutih yang dijual bebas tanpa resep dokter (BPOM RI, 2007).

Krim pencerah yang digunakan bila engandung hidroquinon melebihi 5\% dapat menimbulkan efek samping yang beragam. Efek samping tersebut diantaranya adalah kulit berwarna kemerahan, kulit menjadi kering, kulit seperti terbakar, tersengat, dalam kondisi yang memburuk dapat pula berefek kulit melepuh, pecah-pecah bahkan warna kulit menjadi biru kehitaman (ochronosis) (Wasitaatmadjo, 2007).

\section{SIMPULAN}

Berdasarkan hasil penelitian dan pembahasan dapat ditarik simpulan :

1. Semua sampel krim racikan dokter mengandung hidrokuinon dengan rata-rata $11.9322 \mathrm{ppm}$ atau $1,1932 \%$ dan tidak melebihi aturan BPOM, yaitu 5\% untuk sediaan krim yang diresepkan oleh dokter.

2. Semua sampel krim pencerah wajah bermerk di Kota Denpasar mengandung hidroquinon dengan rata-rata kadar hidroquinon 3.987 ppm atau $0,3987 \%$ dan tidak melebihi dari aturan BPOM, yaitu 
$2 \%$ untuk sediaan krim pemutih yang dijual bebas tanpa resep dokter.

\section{SARAN}

Saran yang dapat disampaikan pada penelitian ini adalah perlu adanya penelitian kadar hidroquinon pada produk-produk pencerah wajah yang tersebar bebas secara illegal atau belum berijin POM NA, sehingga dapat memberikan informasi kepada masyarakat tentang produk yang belum berijin dan kandungan hidroquinonnya.

\section{DAFTAR PUSTAKA}

Anief, Mohammad, 2009, Prinsip Umum dan Dasar Farmakologi, Yogyakarta: Gajah Mada University Press.

Asih, S. B., 2006, Dampak Pengguna Kosmetika Pemutih terhadap Kesehatan Kulit pada Ibu-ibu di RW II Desa Limpung Kecamatan Limpung Kabupaten Batang Jawa, Skripsi, Fakultas Teknik, Universitas Negeri Semarang.

Baran, L, 2008, Textbook of Cosmetic Dermatology, 2ed., London : Martin Dunits Ltd.

BPOM RI, 2007, Kosmetika Mengandung Bahan Berbahaya dan Zat Warna yang Dilarang : Keputusan Kepala BPOM No. HK.00.01.03.1.23.08.11.07517.

Departemen Kesehatan RI, 2005, Farmakope Indonesia, Edisi Keempat, Direktorat jendral Pengawasan Obat dan Makanan, Depkes RI.
Dorland, 2002, Kamus Saku Kedokteran Dorlan edisi 29. Jakarta: Buku Kedokteran EGC.

Draelos and Zoe Diana, 2005. Cosmeceuticals, USA : Elseiver.

Gandjar., I. G., dan Rohman, A., 2007, Kimia Farmasi Analisis, Yogyakarta: Pustaka Pelajar.

Ibrahim Slamet, 2004, Penetapan Kecermatan dan Keseksamaan Metode Kolorimetri Menggunakan Pereaksi Floroglusin Untuk Penetapan kadar Hidrokuinon dalam Krim Pemucatan, ITB : Bandung.

Irnawati, Sahumena, M.H., dan Dewi, W. O., 2016, Analisis Hidrokuinon pada Krim Pemutih Wajah dengan Menggunakan Spektrofotometri UV-Vis. Jurnal Ilmiah Farmasi UNSRAT: Pharmacon. 5 (3): 2302-2493.

Miller, J. N., dan Miller J. C., 2010, Statistics And Chemometries For Analytical Chemistry. Sixth Edition. England: Pearson Education.

Pedro Lopez Garcia, 2007, Determination of Optimum Wavelength and Derivative Order Inspectrophotometry for Quantitation of Hydroquinone in Krim, Revista Brasileira De Ciencias Farmaceuticasbrazilian Journal of Pharmaceutical Sciences.

Saito, E, 1994, Detection of Hydroquinone in a poisoning Case, Journal of Forensic Science, JFSCA, Vol 39, No. 1, Januari 1994, Pp.266-270. 
Siddique, and Saima, 2012. Qualitative and Quantitative Estimation of Hydroquinone in Skin Whitening Cosmetics, Dermatological Science and Application, 2012, 2, 224-228 Doi: 10.4236.

Sunarko, Th dan Riana M. 2007. Analisis Unsur-unsur Toksik dalam Sampel Krim Pemutih Wajah dengan Metode Analisis Aktivasi Neutron. Jurnal Penelitian Pusat Teknologi Bahan Industri Nuklir (BTBIN). Tangerang.
Wasitaatmadja S. M. 2007, Penuntun Ilmu Kosmetik Medik. UI-Press. Jakarta. 